\title{
Evidence of Exercise-Induced Arterial Hypoxemia in Prepubescent Trained Children
}

\author{
CÉDRIC NOURRY, CLAUDINE FABRE, FRÉDÉRIC BART, JEAN-MARIE GROSBOIS, \\ SERGE BERTHOIN, AND PATRICK MUCCI
}

\begin{abstract}
Laboratoire d'Analyse Multidisciplinaire des Pratiques Sportives [C.N., P.M.], UFR STAPS Liévin, Université d'Artois, Chemin du Marquage, 62800 Liévin, France; Laboratoires d'Etudes de la Motricité Humaine [C.F., S.B.], Faculté des Sciences du Sport et de l'Education Physique, Université de Lille 2, 59790 Ronchin, France; and Service de Pneumologie [F.B., J.-M.G.], Hôpital Germon et Gauthier de Béthune, 62660 Beuvry, France
\end{abstract}

\begin{tabular}{|c|c|}
\hline \multicolumn{2}{|c|}{ ABSTRACT } \\
\hline $\begin{array}{l}\text { Exercise-induced arterial hypoxemia (EIAH) is a recognized } \\
\text { phenomenon in highly trained adults. Like adult athletes, prepu- } \\
\text { bescent trained children may develop high-level metabolic de- } \\
\text { mand but with a limited lung capacity in comparison with adults. } \\
\text { The purpose of this investigation was to search for evidence of } \\
\text { EIAH in prepubescent trained children. Twenty-four prepubes- } \\
\text { cent (age: } 10.3 \pm 0.2 \text { y) trained children ( } 10.0 \pm 0.7 \mathrm{~h} \text { of weekly } \\
\text { physical activity) performed pulmonary function tests and a } \\
\text { graded maximal exercise test on a cycle ergometer. EIAH was } \\
\text { defined as a drop of at least } 4 \% \text { from resting level arterial oxygen } \\
\text { saturation }\left(\mathrm{SaO}_{2}\right) \text { measured by pulse oximetry. EIAH was ob- } \\
\text { served in seven children. Forced vital capacity (FVC), ventila- } \\
\text { tory response to exercise }\left(\Delta \dot{\mathrm{V}}_{\mathrm{E}} / \Delta \mathrm{V}_{\mathrm{CO}}\right) \text {, and breathing reserve at } \\
\text { maximal exercise were significantly lower, whereas tidal volume } \\
\text { relative to FVC was higher in hypoxemic children than in } \\
\text { nonhypoxemic children; weekly physical activity and maximal } \\
\text { oxygen uptake were similar. Moreover, positive relationships } \\
\text { were found between SaO }{ }_{2} \text { at maximal exercise and breathing } \\
\text { reserve }(r=0.56 ; p<0.05) \text { or volume relative to FVC }(r= \\
0.70 ; p<0.01) \text { EIAH may occur in prepubescent trained } \\
\text { children with a relatively low maximal oxygen uptake ( } 42 \mathrm{~mL} \text { - } \\
\left.\text { min }{ }^{-1} \cdot \mathrm{kg}^{-1}\right) \text {; however, the mechanisms remain unclear and }\end{array}$ & 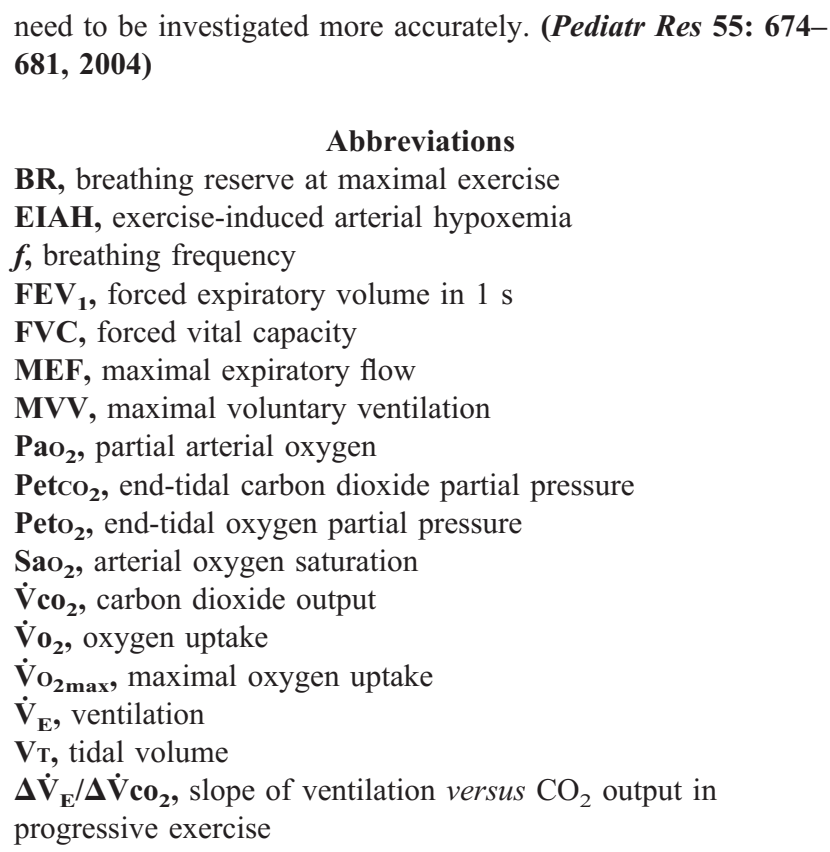 \\
\hline
\end{tabular}

Healthy individuals are commonly considered to be able to maintain arterial oxygenation to meet the increased metabolic demand induced by exercise at sea level. It now is widely recognized, however, that some highly trained adult athletes may reach the limits of their pulmonary function during exercise (1-5). Impaired pulmonary gas exchange leading to exercise-induced arterial hypoxemia (EIAH), characterized by a fall-off of both partial arterial oxygen $\left(\mathrm{PaO}_{2}\right)$ and arterial oxygen saturation $\left(\mathrm{SaO}_{2}\right)$ below resting values, is ample evidence

Received March 4, 2003; accepted September 10, 2003.

Correspondence: Patrick Mucci, UFR STAPS Liévin, Laboratoire d'Analyse Multidisciplinaire des Pratiques et Sportives, Chemin du Marquage, 62800 Liévin, France; e-mail: pmucci@wanadoo.fr

DOI: 10.1203/01.PDR.0000114481.58902.FB
$(2,3,5)$. This phenomenon may reduce aerobic performance in these athletes $(2,3,5,6)$.

EIAH is a multifactorial phenomenon and may be explained in adults by 1) a relative alveolar hypoventilation $(7,8), 2)$ an increase of ventilation-perfusion inequality $\left(\dot{\mathrm{V}}_{\mathrm{A}} / \dot{\mathrm{Q}}_{\mathrm{c}}\right)(9,10)$, and/or 3) an alveolar to capillary diffusion limitation during exercise $(5,9,10)$. Moreover, in adult women, pulmonary gas exchanges may be altered by a reduced lung size $(4,10,11)$. Indeed, a high alveolar-arterial oxygen tension difference during exercise seems to be due to inadequate pulmonary structure/function in women who experience significant EIAH at maximal oxygen uptake $\left(\dot{\mathrm{V}}_{\mathrm{O}_{2 \max }}\right)(4,11)$. This could explain partly why EIAH appears in women for $\dot{\mathrm{V}}_{\mathrm{O}_{2 \max }}$ values lower 
than in men $\left[43 \mathrm{~mL} \cdot \mathrm{min}^{-1} \cdot \mathrm{kg}^{-1}\right.$ (4) versus $60 \mathrm{~mL} \cdot \mathrm{min}^{-1}$ $\left.\cdot \mathrm{kg}^{-1}(2)\right]$.

In trained prepubescent children, $\dot{\mathrm{V}}_{2 \max }$ corrected for body mass can reach high values (12). These values of $\dot{\mathrm{V}}_{\mathrm{O}_{\text {max }}}$ can be above those for which EIAH can be observed in adults. Moreover, in children, lung size and airway flows are lower than in adults (12). We hypothesized that a smaller lung size, in children compared with elite sportsmen, could limit pulmonary function during high-intensity exercise.

Whereas many studies have examined EIAH in adults, only one study, to our knowledge, has focused on EIAH in children during the prepubescent period (13). Laursen et al. (13), who investigated arterial desaturation in exercising active prepubescent girls, did not find significant EIAH during maximal exercise, but in this study, the level of physical activity was not clearly defined and it was assumed that these subjects constituted a general population with only a few sportive children. This choice in population seems discrepant with Dempsey and Wagner (2), who pointed out that adults who exhibit EIAH are generally active. A more recent study in women seems to support this notion, even though the mean of $\dot{\mathrm{V}}_{\mathrm{O}_{\text {max }}}$ achieved in this study was relatively low (e.g. $43 \mathrm{~mL} \cdot \mathrm{min}^{-1} \cdot \mathrm{kg}^{-1}$ ) (4). This raises the question of whether EIAH may be observable in a specific population of sportive prepubescent children and whether inadequate ventilation during exercise might play a role. Thus, the aims of this investigation were to study arterial oxygen $\mathrm{Hb}$ saturation, pulmonary function, and ventilatory response to exercise and the relationships that could exist between these parameters in trained prepubescent children.

\section{METHODS}

\section{Subjects}

The subjects were examined in a hospital pneumology unit. Only prepubertal children (age range: $8-12$ y) with an extracurricular sporting activity $>5 \mathrm{~h} / \mathrm{wk}$ were included. Twentysix prepubescent children [ 16 boys and 10 girls; $10.2 \pm 0.2 \mathrm{y}$; stage 1 of Tanner's scale (14)] who were enrolled in regular sport activity participated in the study. None of the subjects presented cardiac or respiratory problems such as postexercise asthma. Subjects all were members of sports clubs (14 runners, eight swimmers, three football players, one rower) and practiced for $10.0 \pm 0.7 \mathrm{~h} / \mathrm{wk}$ in addition to their normal school physical education lessons $(2 \mathrm{~h} / \mathrm{wk})$. The data were collected during a compulsory medical examination of children involved in sport school sections. The experimental protocol received the approval of the "Comite Consultatif de Protection des Personnes dans la Recherche Biomedical de Lille" to collect the data recorded during medical examinations for research purposes. Before testing was stared, subjects and their parents received a verbal description of the experiment and completed a written, informed consent form.

\section{Experimental design}

Before enrollment in the study, the subjects underwent a complete physical check-up carried out by a physician, aimed at detecting a possible contraindication to the exercise test. The subjects were measured and weighted, and the fat mass percentage was estimated by the skinfold method (15). The level of pubertal maturation was assessed according to Tanner's method (14). A physical activity questionnaire validated for French children (16) was distributed to the parents to assess the physical activity of each child. Then the subjects were familiarized with the experimental material to reduce measurement error. Consecutively, the children performed a maximal graded test. The exercise test was preceded and followed by a pulmonary function test and blood measurements.

\section{Exercise protocol}

The incremental maximal exercise test was performed on a bicycle ergometer with a magnetic brake (800 S; Ergoline, Bitz, Germany) determined according to the size of each subject. Exercise was preceded by a 5-min resting period on the bicycle ergometer. Afterward, the subjects warmed up for $3 \mathrm{~min}$ at $25 \mathrm{~W}$. Then the exercise intensity was increased by steps of $10 \mathrm{~W}$ or $15 \mathrm{~W}$ each minute until exhaustion. The increment depended on the sex and mass of each subject, with the exercise lasting between 8 and $10 \mathrm{~min}$ (17). During the test, the subjects were to maintain a pedaling rate of $60 \mathrm{rpm}$ and were verbally encouraged. The end of the exercise test was assessed to be maximal when at least three of the five following criteria were obtained (12): 1) a maximal heart rate at a value close to the theoretical maximal heart rate, 2) a respiratory exchange ratio $>1,3)$ an increase in oxygen uptake $\left(\mathrm{V}_{2}\right)$ between two steps $<100 \mathrm{~mL} / \mathrm{min}, 4)$ the inability for the subject to maintain a pedaling rate of $60 \mathrm{rpm}$ despite verbal encouragement, and 5) a capillary lactate concentration at least $\geq 7 \mathrm{mmol} / \mathrm{L}$.

\section{Physiologic measurements}

Pulmonary function test. The pulmonary function tests (Ergocard; Medisoft, Dinant, Belgium) were performed $5 \mathrm{~min}$ before and $10 \mathrm{~min}$ after the exercise test. All of the pulmonary function tests were effected by the same technician. Three measures were taken, and only the best was retained to calculate forced vital capacity (FVC); forced expiratory volume in $1 \mathrm{~s}\left(\mathrm{FEV}_{1}\right)$; peak expiratory flow; and maximal expiratory flow at $75 \%\left(\mathrm{MEF}_{75 \%}\right), 50 \%\left(\mathrm{MEF}_{50 \%}\right)$, and $25 \%\left(\mathrm{MEF}_{25 \%}\right)$ of FVC (18). The predicted maximal voluntary ventilation (MVV) was calculated according the following equation (19):

$$
\operatorname{MVV}\left(1 \cdot \min ^{-1}\right)=\mathrm{FEV}_{1} \times 40
$$

Blood measurements. Before exercise, a first finger-tip blood sample of $10 \mu \mathrm{L}$ was collected to measure the blood $\mathrm{Hb}$ concentration ([Hb]), and a second was collected 2-3 min after the end of exercise to measure blood lactate concentration ([La]). Samples were analyzed by spectrophotometric method (Miniphotometer LP20, Dr. Lange, Düsseldorf, Germany).

Cardiopulmonary exercise measurements. A 12-lead ECG (Ergocard; Medisoft) recorded the cardiac response to exercise in real time throughout the exercise test. A breath-by-breath gas analyzer (Ergocard; Medisoft) allowed the measurement of gas exchange during the test, especially ventilation $\left(\dot{\mathrm{V}}_{\mathrm{E}}\right)$, tidal 
volume $(\mathrm{Vt})$, breathing frequency $(f)$, oxygen uptake $\left(\dot{\mathrm{V}}_{2}\right)$, carbon dioxide output $\left(\dot{\mathrm{V}}_{\mathrm{CO}_{2}}\right)$, end-tidal carbon dioxide partial pressure $\left(\mathrm{PetCO}_{2}\right)$, and end-tidal oxygen partial pressure $\left(\right.$ Peto $\left._{2}\right)$. Breathing reserve (BR) was estimated from $\mathrm{FEV}_{1}$, $\mathrm{MVV}$, and $\dot{\mathrm{V}}_{\mathrm{E}}$ reached at maximal exercise, according to the following equation (20):

$$
\mathrm{BR} \%=\left(\mathrm{MVV}-\dot{\mathrm{V}}_{\mathrm{E}}\right) / \mathrm{MVV} \times 100
$$

The slope of ventilation versus $\mathrm{CO}_{2}$ output in progressive exercise $\left(\Delta \dot{\mathrm{V}}_{\mathrm{E}} / \Delta \dot{\mathrm{V}}_{\mathrm{CO}_{2}}\right)$ was individually determined from the slope of the relationship - measured for each subject by linear regression analysis-between $\dot{\mathrm{V}}_{\mathrm{E}}$ and $\dot{\mathrm{V}}_{\mathrm{CO}_{2}}$ recorded between the onset of exercise and occurrence of the respiratory compensation point (21), i.e. maximal data were never taken into account in the determination of $\Delta \dot{\mathrm{V}}_{\mathrm{E}} / \Delta \dot{\mathrm{V}}_{\mathrm{CO}_{2}} . \dot{\mathrm{V}}_{\mathrm{E}}$ and $\dot{\mathrm{V}}_{\mathrm{CO}_{2}}$ were plotted during submaximal exercise (i.e. until the occurrence of respiratory compensation point), and the $\Delta \dot{\mathrm{V}}_{\mathrm{E}} / \Delta \dot{\mathrm{V}}_{\mathrm{CO}_{2}}$ was the slope of the straight line going through these plots (Fig. 1).

$\mathrm{SaO}_{2}$ measurement and EIAH determination. The values of $\mathrm{SaO}_{2}$ were obtained by a noninvasive method: a pulse ear oximeter (3800 S; Datex Ohmeda, Madison, WI; U.S.A.). Before exercise, the ear was warmed with a vasodilator ointment and the probe was kept in place on the ear by means of adhesive tape to avoid potential problems in signal recording. Moreover, the pulse oximeter evaluated waveform signal quality pulse by pulse, indicating when problems associated with blood flow to the ear might influence $\mathrm{SaO}_{2}$. Consequently, two subjects were excluded from our population because of nonuniform waveform signal during exercise. Before exercise, $\mathrm{SaO}_{2}$ was recorded and averaged over $3 \mathrm{~min}$, whereas during exercise, $\mathrm{SaO}_{2}$ was recorded during the last $10 \mathrm{~s}$ of each minute only when the accuracy of the signal was optimal. The pulse oximeter was automatically calibrated before each experiment. We are assured of the validity of our particular pulse oximeter by comparing the development of hypoxemia estimated from our pulse oximeter and the EIAH evidenced by measurement of blood gazes in subjects who were evaluated in a hospital (unpublished data). The occurrence criterion of EIAH was

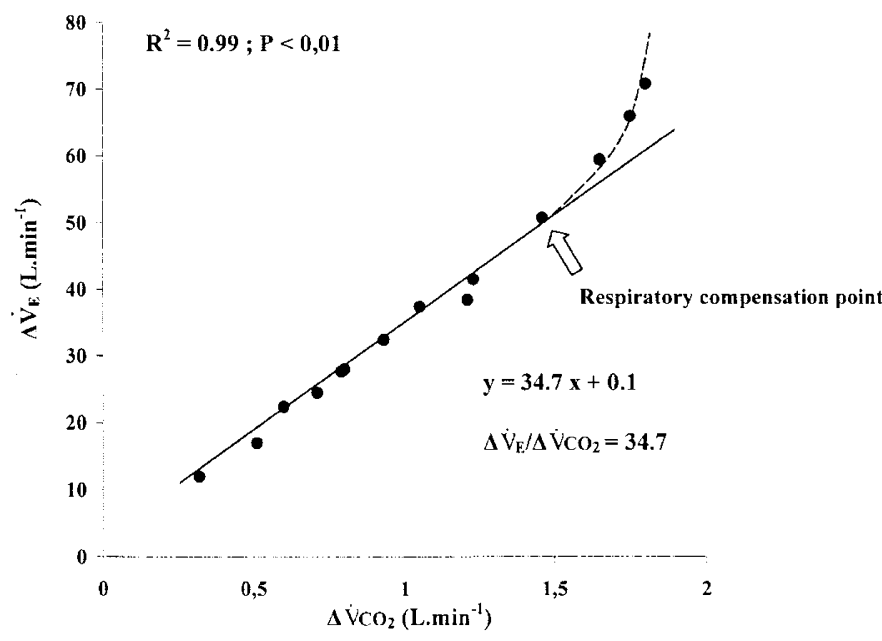

Figure 1. Representative linear regression between minute ventilation $\left(\Delta \dot{V}_{\mathrm{E}}\right)$ and carbon dioxide output $\left(\Delta \dot{\mathrm{V}} \mathrm{CO}_{2}\right)$ during submaximal exercise in one child. fixed at a drop of at least $4 \%$ in $\mathrm{SaO}_{2}$ between the values at rest and at the end of the exercise $(5,22)$.

\section{Statistical analysis}

All values are given as means \pm SEM. SigmaStat 2.0 (SPSS Science, Chicago, IL; U.S.A.) was used for statistical analysis. Data were compared between hypoxemic subjects and nonhypoxemic subjects with a Mann-Whitney rank sum test. Pulmonary function was compared in each group with a Wilcoxon signed rank test. The time course of $\mathrm{SaO}_{2}$ during exercise was analyzed by a Friedman repeated-measures ANOVA on ranks. Spearman nonparametric linear regression tests were used to search for correlations between the different parameters. The level of significance was set at $p<0.05$.

\section{RESULTS}

Data analysis identified two groups formed by subjects who exhibited EIAH and those who did not. Seven subjects who exhibited EIAH (five boys and two girls) composed the hypoxemic group $(\mathrm{H})$. The nonhypoxemic group $(\mathrm{NH})$ was made up of the 17 remaining subjects (11 boys and six girls). The $\mathrm{H}$ group was composed of four subjects who exhibited mild EIAH, defined as an end-exercise $\mathrm{SaO}_{2}$ of $93-95 \%$, and three subjects with moderate EIAH, defined as an $\mathrm{SaO}_{2}$ of $88-93 \%$.

$\mathrm{Sao}_{2}$ during the muscular exercise test. The two groups exhibited a difference in $\mathrm{SaO}_{2}$ at 25\% $(p<0.05), 50 \%(p<$ $0.05), 75 \%$, and $100 \%(p<0.01)$ of maximal power. In the $\mathrm{H}$ group, the exercise $\mathrm{SaO}_{2}$ was significantly lower than at rest for relative power, ranging between 75 and $100 \%$ of maximal aerobic power $(p<0.05)$. The NH group exhibited a significant difference from baseline value only at $100 \%$ of maximal power (Fig. 2).

Comparisons between groups $\mathrm{H}$ and $\mathrm{NH}$. The mean value of weekly physical activity was not significantly different between the $\mathrm{H}$ group and the NH group. The two groups were homogeneous with regard to anthropometric characteristics (Table 1). Before exercise, the NH group showed a signifi-

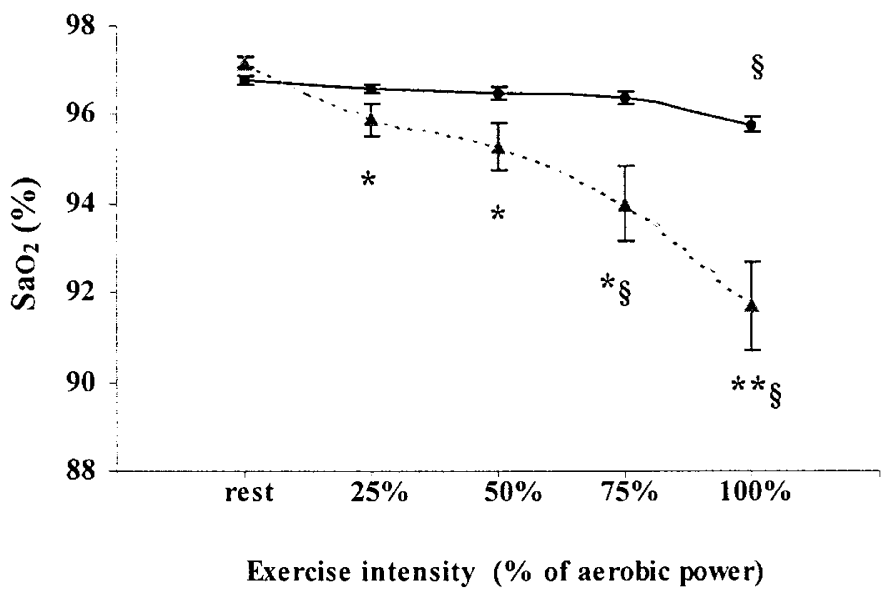

Figure 2. Change in $\mathrm{SaO}_{2}$ during incremental exercise. The exercise intensity is expressed as a percentage of maximal aerobic power achieved during the incremental exercise. $\boldsymbol{O}$, nonhypoxemic subjects; $\mathbf{\Delta}$, hypoxemic subjects. Significant difference between the two groups: ${ }^{*} p<0.05 ;{ }^{*} p<0.01$. Significant difference with rest in hypoxemic group: $\$ p<0.05$. 
Table 1. Subject characteristics

\begin{tabular}{lrrcr}
\hline & & $\begin{array}{c}\mathrm{NH} \\
(n=17)\end{array}$ & $\begin{array}{c}\text { Girls } \\
(n=8)\end{array}$ & \multicolumn{1}{c}{$\begin{array}{c}\text { Boys } \\
(n=16)\end{array}$} \\
\hline Age (y) & $10.1 \pm 0.3$ & $10.4 \pm 0.3$ & $9.4 \pm 0.3^{*}$ & $10.8 \pm 0.3$ \\
Body mass (kg) & $31.9 \pm 2.1$ & $35.2 \pm 1.1$ & $32.8 \pm 1.8$ & $34.9 \pm 1.2$ \\
Height (cm) & $138.9 \pm 3.3$ & $144.4 \pm 2.2$ & $137.5 \pm 2.3$ & $145.4 \pm 2.4$ \\
Fat mass (\%) & $13.3 \pm 1.3$ & $14.1 \pm 0.9$ & $16.6 \pm 0.9 *$ & $11.9 \pm 0.6$ \\
Physical activity & $10.1 \pm 1.4$ & $9.9 \pm 0.8$ & $9.6 \pm 0.9$ & $9.5 \pm 1.0$ \\
$\quad$ per week (h) & & & & \\
{$[\mathrm{Hb}](\mathrm{g} / \mathrm{dL})$} & $12.1 \pm 0.3$ & $12.3 \pm 0.4$ & $12.5 \pm 0.5$ & $12.1 \pm 0.3$ \\
\hline
\end{tabular}

Values are means \pm SEM.

* Significant difference between girls and boys $(p<0.05)$.

cantly greater $\mathrm{FVC}$ and $\mathrm{FVC}$ /height than the $\mathrm{H}$ group ( $p<$ $0.05)$. In both groups, no significant change was found between pre- and postexercise in pulmonary function test results (Table 2). During submaximal exercise, $\Delta \dot{\mathrm{V}}_{\mathrm{E}} / \Delta \dot{\mathrm{V}}_{\mathrm{CO}_{2}}$ was significantly lower in $\mathrm{H}$ subjects than in $\mathrm{NH}$ subjects $(27.8 \pm 2.4$ versus $35.7 \pm 1.6$, respectively; $p<0.05$; Fig. 3 ). Breathing pattern was not different between $\mathrm{H}$ and $\mathrm{NH}$ at $25 \%, 50 \%, 75 \%$, and $100 \%$ of aerobic power (Fig. 4). No difference was found in $\mathrm{PetO}_{2}$ and $\mathrm{Petco}_{2}$ at each stage of exercise between $\mathrm{H}$ and $\mathrm{NH}$ subjects (Fig. 5). At maximal exercise (Table 3), $\dot{\mathrm{V}}_{2 \max }$, expressed in $\mathrm{L} / \mathrm{min}$ or $\mathrm{mL} \cdot \mathrm{min}^{-1} \cdot \mathrm{kg}^{-1}$ and in percentage of predicted $(121.5 \pm 5.4 \%$ versus $110.4 \pm 2.4 \%$, respectively $)$ was similar in $\mathrm{H}$ and $\mathrm{NH}$ groups. However, $\mathrm{SaO}_{2}(p<0.01)$ and BR $(p<0.01)$ were lower whereas $\mathrm{V}_{\mathrm{T}} / \mathrm{FVC}(p<0.01)$ was higher in $\mathrm{H}$ compared with $\mathrm{NH}$. The other maximal parameters were not different between $\mathrm{H}$ and $\mathrm{NH}$. After exercise, the [La] was not different between group $\mathrm{H}(12.1 \pm 2.1$ $\mathrm{mmol} / \mathrm{L})$ and group $\mathrm{NH}(9.1 \pm 0.9 \mathrm{mmol} / \mathrm{L})$.

Comparisons between girls and boys. Physical activity was not significantly different between girls $(9.6 \pm 0.9 \mathrm{~h} / \mathrm{wk})$ and boys $(9.5 \pm 1.0 \mathrm{~h} / \mathrm{wk})$. Girls were slightly younger than boys $(p<0.05)$. Anthropometric characteristics were not statically different between sexes except for fat mass percentage $(p<$ 0.05; Table 1). At rest, FVC was not statistically different between girls $(1.82 \pm 0.15)$ and boys $(2.22 \pm 0.17)$. No difference was found for resting value of $\mathrm{FEV}_{1}$ between girls $(1.75 \pm 0.04)$ and boys $(2.05 \pm 0.12)$. Resting value of peak expiratory flow was not different between girls $(3.65 \pm 0.24)$ and boys $(4.20 \pm 2.11)$. No difference was found between preand postexercise pulmonary function tests in girls and boys. Postexercise spirometric data were not significantly different between girls and boys. During submaximal exercise, $\Delta \dot{\mathrm{V}}_{\mathrm{E}} /$ $\Delta \dot{\mathrm{V} C O} \mathrm{O}_{2}$ was similar in girls and boys $(32.4 \pm 3.2$ versus 33.4 \pm 1.5 , respectively). At maximal exercise (Table 4), girls exhibited lower $\dot{\mathrm{V}}_{\mathrm{O}_{2 \max }}(p<0.01)$, maximal aerobic power $(p<0.05)$, Vт $(p<0.05)$, and $\dot{\mathrm{V}}_{\mathrm{E}}(p<0.05)$ than boys. Percentage of predicted value of $\dot{\mathrm{V}}_{2 \max }$ was not significantly different between girls and boys (107.2 $\pm 4.4 \%$ versus $116.9 \pm$ $2.7 \%$, respectively). $\mathrm{SaO}_{2}$ at maximal exercise was higher in girls than in boys $(p<0.01)$. The other maximal parameters were not significantly different between girls and boys. The [La] achieved after exercise was not different between girls $(9.0 \pm 1.7 \mathrm{mmol} / \mathrm{L})$ and boys $(10.4 \pm 0.8 \mathrm{mmol} / \mathrm{L})$.

Relationships between the different parameters. In both groups, the $\mathrm{SaO}_{2}$ at maximal exercise was significantly related to the $\mathrm{BR}(n=24, r=0.43, p<0.05)$ and the $\mathrm{Vt}$ relative to FVC $(\mathrm{VT} / \mathrm{FVC})(n=24, r=0.70, p<0.01$; Fig. 6$)$.

\section{DISCUSSION}

Our results showed that EIAH occurred in some prepubescent trained children (seven of 24 subjects, $\sim 30 \%$ ) when they performed a graded exercise test to exhaustion. The development of this EIAH was associated with lower FVC and BR in hypoxemic than in nonhypoxemic subjects matched for sporting activity level and $\dot{\mathrm{V}}_{2 \max }$.

EIAH in prepubescent children. A concern in this study was to evaluate arterial saturation in oxygen during a graded test performed until exhaustion in children. Generally, an arterial blood sample is drawn to measure $\mathrm{PaO}_{2}$ (2). This technique would have been very invasive and is ethically unfeasible in children (12). As a consequence, the EIAH was investigated using a less aggressive noninvasive method (pulse oximetry), limiting, as advised by Rowland (12), the stress imposed by such a study. Use of pulse oximetry has been validated $(23,24)$. However, even though the evaluation of $\mathrm{SaO}_{2}$ by pulse oximetry can provide qualitative information, it is somewhat riskier to use the $\mathrm{SaO}_{2}$ evaluated noninvasively as quantitative information (25). Thus, we must be cautious regarding the relationships found between some parameters and $\mathrm{SaO}_{2}$ evaluated during exercise. Finally, EIAH was considered to exist when $\mathrm{SaO}_{2}$ fell of at least $4 \%$ between the values at rest and at the end of the exercise $(5,22)$. The literature suggests that a drop of at least $4 \%$ in $\mathrm{SaO}_{2}$ is sufficient to underscore a significant decrease in $\mathrm{SaO}_{2}$ during exercise (25) and define EIAH $(5,22)$. The results of our study showed for the time first that EIAH occurs in prepubescent subjects. EIAH appeared in our study at a relatively low $\dot{\mathrm{V}}_{2 \max }$ (expressed in $\mathrm{mL} \cdot \mathrm{min}^{-1}$ $\cdot \mathrm{kg}^{-1}$ ) compared with the levels generally observed in male adults $(2,3,5)$. Indeed, the $\dot{V}_{o_{2 \max }}$ reported in hypoxemic children ranged from 42.4 to $62.0 \mathrm{~mL} \cdot \mathrm{min}^{-1} \cdot \mathrm{kg}^{-1}$ versus 57 $\mathrm{mL} \cdot \min ^{-1} \cdot \mathrm{kg}^{-1}$ observed in adult men (2). However, the $\dot{\mathrm{V}} \mathrm{O}_{2 \max }$ of these children was comparable to the level observed in adult women $\left(43 \mathrm{~mL} \cdot \mathrm{min}^{-1} \cdot \mathrm{kg}^{-1}\right)$ (4). In recent studies, these relatively low values in $\dot{\mathrm{V}}_{2 \max }$ for the onset of EIAH in women compared with men was partly explained by inadequate pulmonary structure/function, i.e. too low lung size versus high metabolic demand $(4,11)$. Our findings would be in agreement with these observations in women because in hypoxemic children, we found that EIAH was associated with lower FVC and FVC/height. In addition, at maximal exercise, we found in hypoxemic subjects lower BR and higher $\mathrm{V}_{\mathrm{T}} / \mathrm{FVC}$ than in nonhypoxemic subjects, despite the same aerobic demand during exercise (i.e. $\dot{\mathrm{V}}_{\mathrm{O}_{2 \max }}$ ) and a high weekly physical activity similar to that in nonhypoxemic subjects. Hypoxemic subjects seem to approach more closely their mechanical lung limits than nonhypoxemic subjects. However, this seems not to affect ventilation, which supposes that ventilation is adequate despite low $\mathrm{SaO}_{2}$ as discussed below.

In the $\mathrm{H}$ group, $\mathrm{SaO}_{2}$ was lower than in the $\mathrm{NH}$ group from $25 \%$ up to $100 \%$ of maximal power and was significantly decreased from resting values from $75 \%$, which is in agreement with previous studies in adults $(26,27)$. Indeed, Rice et 
Table 2. Pulmonary function tests before and after exercise in $\mathrm{H}$ and $\mathrm{NH}$

\begin{tabular}{|c|c|c|c|c|}
\hline & \multicolumn{2}{|c|}{$\mathrm{H}(n=7)$} & \multicolumn{2}{|c|}{$\mathrm{NH}(n=17)$} \\
\hline & Measured & $\%$ Predicted & Measured & $\%$ Predicted \\
\hline \multicolumn{5}{|l|}{ Rest } \\
\hline FVC/height (L/m) & $1.22 \pm 0.06^{*}$ & & $1.55 \pm 0.10$ & \\
\hline $\mathrm{FEV}_{1}(\mathrm{~L})$ & $1.67 \pm 0.90$ & $102.33 \pm 5.77$ & $2.03 \pm 0.12$ & $95.59 \pm 4.49$ \\
\hline $\mathrm{FEV}_{1} / \mathrm{FVC}(\%)$ & $98.4 \pm 0.9$ & $115.1 \pm 0.8$ & $91.7 \pm 2.0$ & $109.2 \pm 1.9$ \\
\hline $\mathrm{MEF}_{50 \%}(\mathrm{~L} / \mathrm{s})$ & $2.66 \pm 0.26$ & $90.29 \pm 6.48$ & $2.95 \pm 0.18$ & $91.47 \pm 5.70$ \\
\hline $\mathrm{MEF}_{25 \%}(\mathrm{~L} / \mathrm{s})$ & $1.98 \pm 0.30$ & $105.57 \pm 11.76$ & $1.65 \pm 0.18$ & $90.06 \pm 9.15$ \\
\hline \multicolumn{5}{|l|}{ Postexercise } \\
\hline $\mathrm{FVC}(\mathrm{L})$ & $1.64 \pm 0.10$ & $83.43 \pm 7.29$ & $2.05 \pm 0.18$ & $92.64 \pm 4.58$ \\
\hline FVC/height (L/m) & $1.19 \pm 0.07$ & & $1.42 \pm 0.10$ & \\
\hline $\mathrm{FEV}_{1}(\mathrm{~L})$ & $1.62 \pm 0.10$ & $96.86 \pm 8.33$ & $1.87 \pm 0.15$ & $101.91 \pm 4.83$ \\
\hline
\end{tabular}

Values are means \pm SEM.

* Significant difference between $\mathrm{H}$ and NH $(p<0.05)$.

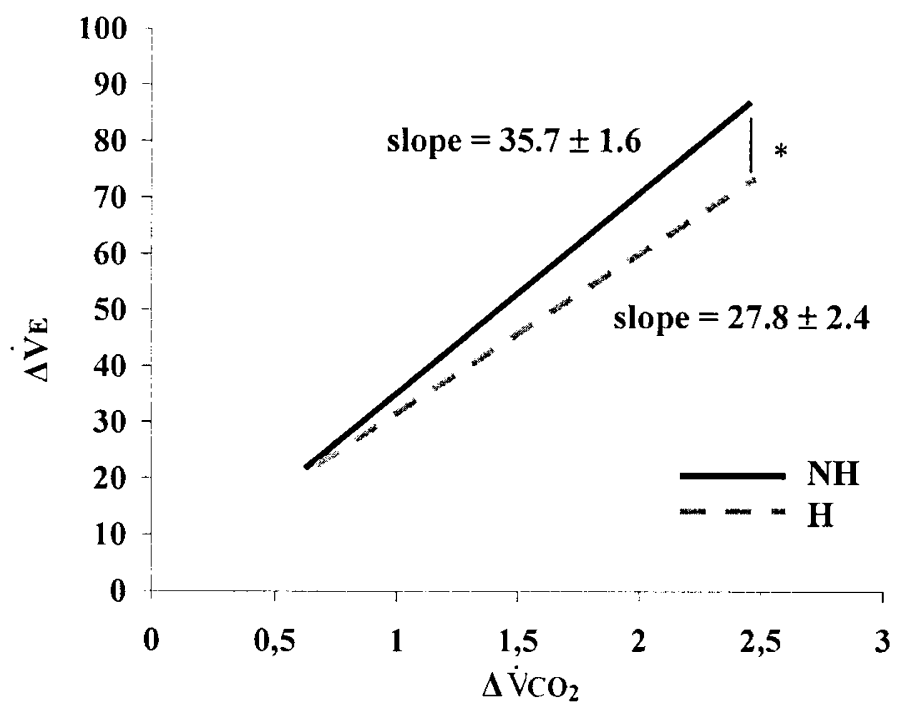

Figure 3. Comparison in ventilatory response to exercise $\left(\Delta \dot{\mathrm{V}}_{\mathrm{E}} / \Delta \dot{\mathrm{V}}_{\mathrm{CO}_{2}}\right)$ between hypoxemic subject (- - ) and nonhypoxemic subjects (-) Significant difference between hypoxemic and nonhypoxemic subject: ${ }^{*} p<0.05$

al. (26) showed a decrease in $\mathrm{PaO}_{2}$ from $40 \%$ of $\dot{\mathrm{V}}_{2 \text { max }}$ in adult cyclists onward. In the same way, Aguilaniu et al. (27) reported significantly higher values of alveolar to arterial difference in oxygen pressure from $30 \% \dot{\mathrm{V}}_{\mathrm{O}_{\max }}$ in subjects who exhibited gas exchange disturbance than in control subjects. Therefore, the decrease in $\mathrm{SaO}_{2}$ in group $\mathrm{H}$ likely reflected an impairment of pulmonary gas exchange, which could begin at submaximal exercise as it has been reported in adults $(2,5,7$, 8). We noted that the $\mathrm{NH}$ group showed a significant decrease in $\mathrm{SaO}_{2}$ at maximal exercise that was $<4 \%$ and likely may be explained by the normal decreasing $\mathrm{pH}$, increasing temperature, and resultant rightward shift of the $\mathrm{Hb}-\mathrm{O}_{2}$ dissociation curve at high exercise intensity (11). In the present study, the onset of EIAH in children was not consistent with the Laursen

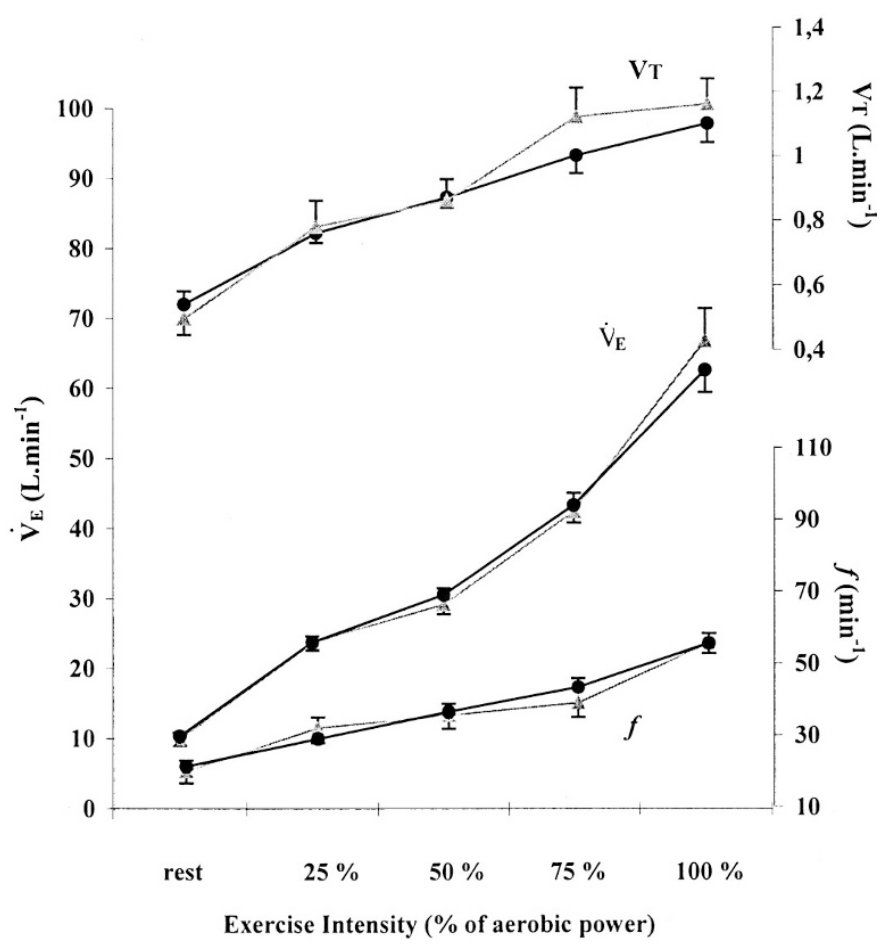

Figure 4. Change in $\dot{\mathrm{V}}_{\mathrm{E}}, \mathrm{VT}$, and $f$ during incremental exercise. The exercise intensity is expressed as a percentage of maximal aerobic power achieved during the incremental exercise. $\bullet$, nonhypoxemic subjects; $\Delta$, hypoxemic subjects.

et al. study (13), which did not disclose any hypoxemic subjects in a population of active prepubescent girls. These seemingly contradictory results between the two studies could be related to differences in the definition of "active" subjects and/or in criteria used to identify EIAH. First, in the Laursen et al. study (13), the term "active" was unclear because the habitual activity was not reported. It may have corresponded to regular low-intensity or recreational exercise, whereas our 


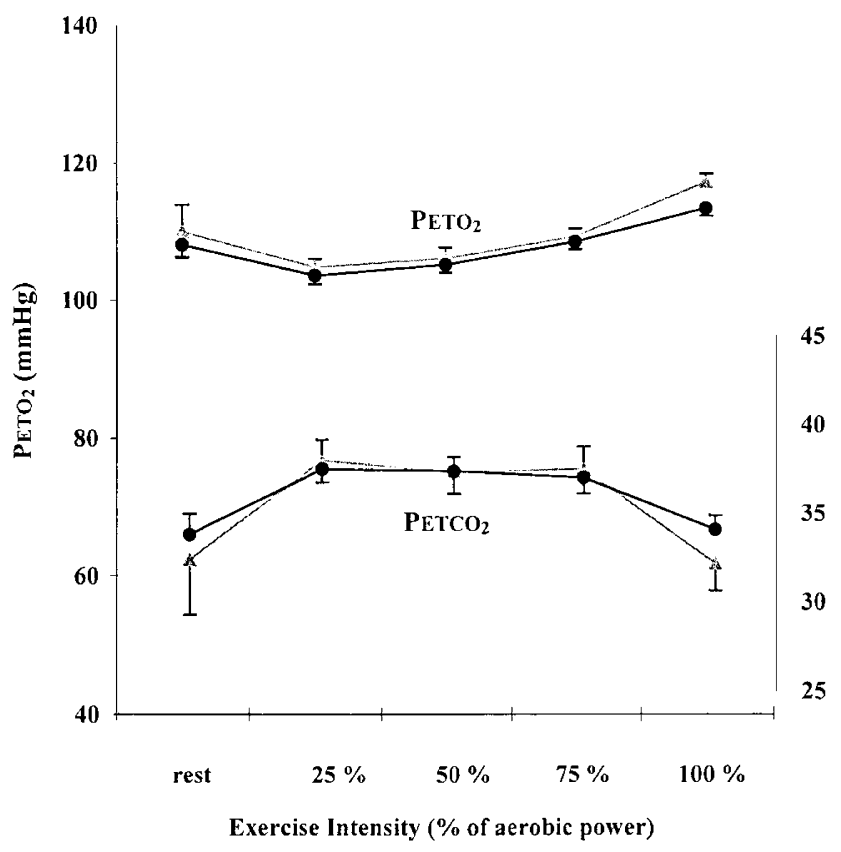

Figure 5. Change in $\mathrm{Peto}_{2}$ and $\mathrm{Petco}_{2}$ during incremental exercise. The exercise intensity is expressed as a percentage of maximal aerobic power achieved during the incremental exercise. $\mathbf{O}$, nonhypoxemic subjects; $\triangle$, hypoxemic subjects.

Table 3. Functional data at maximal exercise in $H$ and $N H$

\begin{tabular}{lcc}
\hline & $\begin{array}{c}\mathrm{H} \\
(n=7)\end{array}$ & $\begin{array}{c}\mathrm{NH} \\
(n=17)\end{array}$ \\
\hline$\dot{\mathrm{V}}_{2 \max }(\mathrm{L} / \mathrm{min})$ & $1.60 \pm 0.14$ & $1.64 \pm 0.09$ \\
$\dot{\mathrm{V}}_{2 \text { max }}\left(\mathrm{mL} \cdot \mathrm{min}^{-1} \cdot \mathrm{kg}^{-1}\right)$ & $50.6 \pm 2.7$ & $46.4 \pm 1.7$ \\
$\mathrm{P}_{\max }(\mathrm{W})$ & $134.3 \pm 8.8$ & $129.7 \pm 6.4$ \\
$\dot{\mathrm{V}}_{\mathrm{E}}(\mathrm{L} / \mathrm{min})$ & $66.9 \pm 4.6$ & $62.7 \pm 3.3$ \\
$\dot{\mathrm{V}}_{\mathrm{E}} / \dot{\mathrm{V}}_{2}$ & $39.3 \pm 2.4$ & $36.4 \pm 1.1$ \\
$\dot{\mathrm{V}}_{\mathrm{E}} / \dot{\mathrm{V}}_{\mathrm{CO}_{2}}$ & $35.3 \pm 1.6$ & $35.7 \pm 1.5$ \\
$\mathrm{VT}_{\mathrm{T}}(\mathrm{L} / \mathrm{min})$ & $1.10 \pm 0.06$ & $1.12 \pm 0.08$ \\
$f\left(\mathrm{~min}^{-1}\right)$ & $55.6 \pm 2.8$ & $56.8 \pm 4.0$ \\
$\left.\mathrm{VT}_{\mathrm{TVC}} / \%\right)$ & $70.4 \pm 4.9 \dagger$ & $53.4 \pm 3.9$ \\
$\mathrm{BR}(\%)$ & $-0.6 \pm 5.1 *$ & $20.6 \pm 3.6$ \\
$\mathrm{SaO}_{2}(\%)$ & $91.3 \pm 0.8 \dagger$ & $95.7 \pm 0.2$ \\
$\mathrm{Peto}_{2}(\mathrm{mmHg})$ & $117.3 \pm 1.3$ & $113.4 \pm 1.1$ \\
$\mathrm{Petco}_{2}(\mathrm{mmHg})$ & $31.6 \pm 1.3$ & $34.4 \pm 1.0$ \\
\hline
\end{tabular}

Values are means \pm SEM.

$\mathrm{P}_{\text {max }}$, maximal aerobic power; $\dot{\mathrm{V}}_{\mathrm{E}} / \dot{\mathrm{V}}_{2}$, ventilatory equivalent for oxygen; $\dot{\mathrm{V}}_{\mathrm{E}} / \grave{\mathrm{V}}_{\mathrm{CO}_{2}}$, ventilatory equivalent for carbon dioxide.

* Significant difference between $\mathrm{H}$ an NH $(p<0.05)$.

$\dagger$ Significant difference between $\mathrm{H}$ and $\mathrm{NH}(p<0.01)$.

subjects were regularly enrolled in sports training programs (see Methods). All of the children in our study were "sportive" even though their mean $\dot{V}_{O_{2 \max }}$ was not very high. Moreover, regular training is a common status in hypoxemic adults (2) and could be a determinant factor in the onset of arterial desaturation during exercise. This hypothesis is supported by the results of Ohuchi et al. (28) and by the observation of unpublished data from our laboratory showing no alteration in $\mathrm{PaO}_{2}$ or $\mathrm{SaO}_{2}$ during incremental exercise in less active prepubescent children. Second, we defined EIAH as a drop in $\mathrm{SaO}_{2}$ of at least $4 \%$ from baseline $(5,22)$, which takes into account the individual's resting value, whereas Laursen et al. (13)
Table 4. Functional data at maximal exercise in girls and boys

\begin{tabular}{lcc}
\hline & $\begin{array}{c}\text { Girls } \\
(n=8)\end{array}$ & $\begin{array}{c}\text { Boys } \\
(n=16)\end{array}$ \\
\hline$\dot{\mathrm{V}}_{2 \max }(\mathrm{L} / \mathrm{min})$ & $1.31 \pm 0.06 \dagger$ & $1.79 \pm 0.08$ \\
$\dot{\mathrm{V}}_{2 \max }\left(\mathrm{mL} \cdot \mathrm{min}^{-1} \cdot \mathrm{kg}^{-1}\right)$ & $40.2 \pm 1.8 \dagger$ & $51.4 \pm 1.1$ \\
$\mathrm{P}_{\max }(\mathrm{W})$ & $105.6 \pm 5.8^{*}$ & $143.8 \pm 4.5$ \\
$\dot{\mathrm{V}}_{\mathrm{E}}(\mathrm{L} / \mathrm{min})$ & $54.2 \pm 4.8^{*}$ & $68.8 \pm 2.4$ \\
$\dot{\mathrm{V}}_{\mathrm{E}} / \dot{\mathrm{V}}_{2}$ & $39.0 \pm 2.8$ & $36.3 \pm 0.8$ \\
$\dot{\mathrm{V}}_{\mathrm{E}} / \dot{\mathrm{V}}$ & $35.0 \pm 2.0$ & $35.9 \pm 1.4$ \\
$\mathrm{VT}(\mathrm{L} / \mathrm{min})$ & $1.00 \pm 0.06^{*}$ & $1.19 \pm 0.06$ \\
$f\left(\mathrm{~min}^{-1}\right)$ & $53.1 \pm 4.4$ & $57.6 \pm 2.5$ \\
$\mathrm{VT} / \mathrm{FVC}(\%)$ & $58.2 \pm 6.9$ & $57.9 \pm 4.1$ \\
$\mathrm{BR}(\%)$ & $9.5 \pm 8.3$ & $13.0 \pm 4.2$ \\
$\mathrm{SaO}_{2}(\%)$ & $96.8 \pm 0.3 \dagger$ & $94.3 \pm 0.6$ \\
$\mathrm{Peto}_{2}(\mathrm{mmHg})$ & $113.8 \pm 2.1$ & $115.1 \pm 0.9$ \\
$\mathrm{Petco}_{2}(\mathrm{mmHg})$ & $34.3 \pm 2.0$ & $33.1 \pm 0.7$ \\
\hline
\end{tabular}

Values are means \pm SEM.

* Significant difference between girls and boys $(p<0.05)$.

$\dagger$ Significant difference between girls and boys $(p<0.01)$.

defined EIAH as a fall in $\mathrm{Sao}_{2}$ below 91\% $(5,6)$. However, setting the threshold too low could lead to neglecting a class of mild hypoxemic subjects (5), i.e. subjects exhibiting an $\mathrm{SaO}_{2}$ from 93 to $91 \%$ (2). In fact, applying the $4 \%$ fall in $\mathrm{SaO}_{2}$ as the cutoff point for EIAH to the subjects in Laursen's study (13) would have identified two girls with mild hypoxemia. In addition, it should be noted that in adult women, a 3\% decrease in $\mathrm{SaO}_{2}$ from resting value has a significant detrimental effect on $\dot{\mathrm{V}}_{2 \max }$ (29), further supporting our choice of the $4 \% \mathrm{SaO}_{2}$ drop-off as the definition of EIAH (5).

Explanatory hypothesis in children. A major mechanism in EIAH in adults is a ventilatory limitation during exercise, termed relative hypoventilation $(5,7)$. In adults, the submaximal decrease in $\mathrm{SaO}_{2}$ seems explained by a relative hypoventilation associated with a $\dot{V}_{\mathrm{A}} / \dot{\mathrm{Q}} \mathrm{c}$ mismatch $(26,27) \dot{\mathrm{V}}_{\mathrm{A}} / \dot{\mathrm{Q}}_{\mathrm{c}}$ mismatch was not measured in the present study; however, we found lower values of $\Delta \dot{\mathrm{V}}_{\mathrm{E}} / \Delta \dot{\mathrm{V}}_{\mathrm{CO}_{2}}$ during submaximal exercise in hypoxemic children (Fig. 2). This result shows that hypoxemic subjects seem to regulate arterial $\mathrm{CO}_{2}$ pressure at higher $\mathrm{CO}_{2}$ set point than nonhypoxemic subjects $(21,30)$. Studies reported a significant relationship between the $\Delta \dot{\mathrm{V}}_{\mathrm{E}} / \Delta \dot{\mathrm{V}}_{\mathrm{CO}_{2}}$ and the ventilatory sensitivity to inhaled $\mathrm{CO}_{2}$ at rest (31) and during exercise (32). Thus, the low ventilatory response to exercise could be due to a low $\mathrm{CO}_{2}$ chemoresponsiveness (33) and seems in favor of a relative hypoventilation during submaximal workload as reported in adults $(7,8,22)$. Nevertheless, no difference was found between hypoxemic and nonhypoxemic subjects in breathing pattern (i.e. $\dot{\mathrm{V}}_{\mathrm{E}}, \mathrm{V}_{\mathrm{T}}, f$ ), Peto ${ }_{2}$, and $\mathrm{PetCO}_{2}$ during exercise, which led us to be very cautious with the interpretation of the lower $\Delta \dot{\mathrm{V}}_{\mathrm{E}} / \Delta \dot{\mathrm{V}}_{\mathrm{CO}_{2}}$ in hypoxemic subjects during submaximal exercise. In addition, this suggests that other mechanisms as $\dot{\mathrm{V}}_{\mathrm{A}} / \dot{\mathrm{Q}}_{\mathrm{c}}$ mismatch, which increases with low lung capacity (9), could be involved in early onset of the differences in $\mathrm{SaO}_{2}$ between hypoxemic and nonhypoxemic children $(26,27)$. Obviously, these speculations need further investigation.

At maximal exercise, hypoxemic subjects tend to ventilate more $\left(\dot{\mathrm{V}}_{\mathrm{E}}, \dot{\mathrm{V}}_{\mathrm{E}} / \dot{\mathrm{V}}_{2}, \dot{\mathrm{V}}_{\mathrm{E}} / \dot{\mathrm{V}}_{\mathrm{CO}_{2}}\right.$, and $\left.\mathrm{Pet}_{2}\right)$ than nonhypoxemic subjects despite nonsignificant difference. Moreover, hypoxemic subjects seem to ventilate nearer to their mechanical lung 

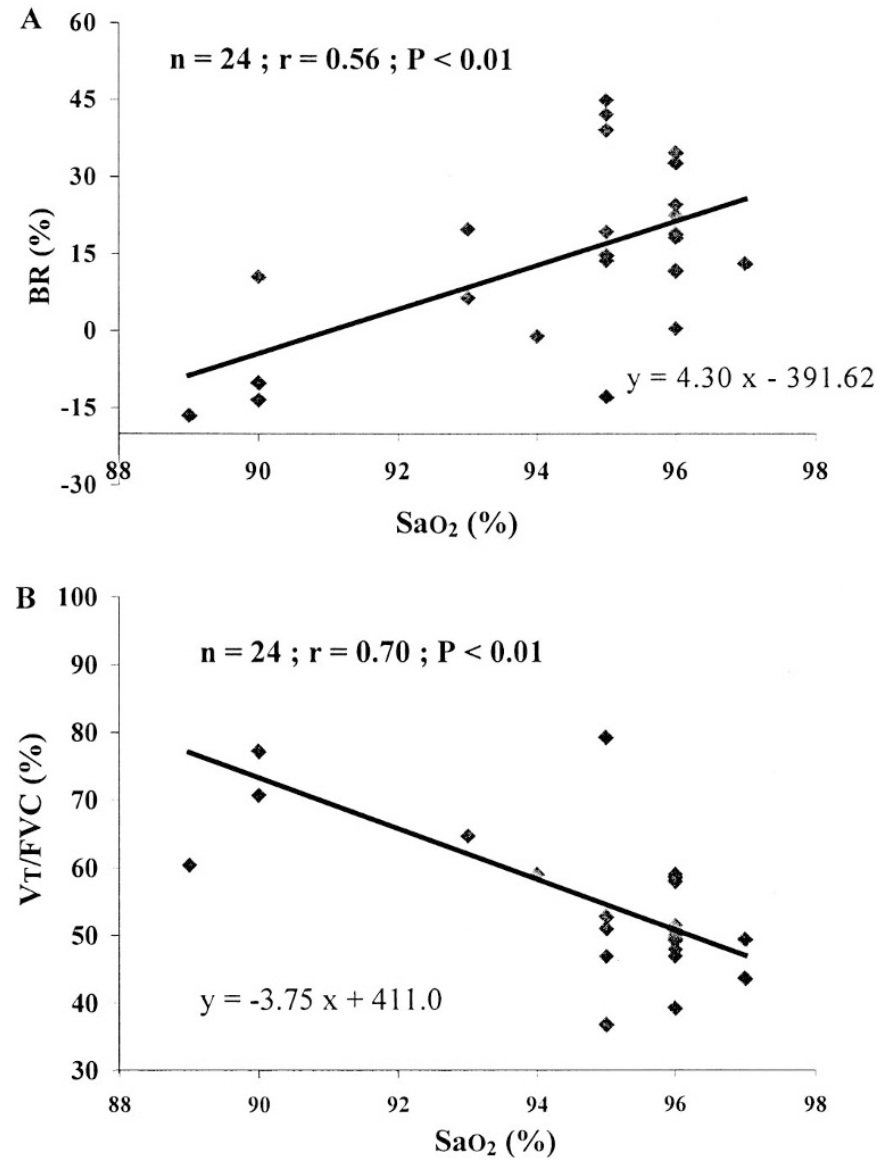

Figure 6. (A) Relationship between $\mathrm{SaO}_{2}$ and $\mathrm{BR}$ at maximal exercise. (B) Relationship between $\mathrm{SaO}_{2}$ and $\mathrm{VT}$ relative to FVC.

limits than nonhypoxemic subjects (i.e. low BR, high $\mathrm{V}_{\mathrm{T}} /$ $\mathrm{FVC}$ ). Indeed, the lower lung size measured in hypoxemic children associated with likely higher ventilation could explain the lower BR and the higher $\mathrm{VT} / \mathrm{FVC}$ at maximal exercise than in nonhypoxemic subjects. Further studies would be necessary to investigate the flow-volume curve during exercise added to measurement of vital capacity and total lung capacity, which are better indicators of lung capacity than FVC. This would enable a more precise quantification of the contribution of a possible mechanical lung constraint in hypoxemic subjects. The BR found in the nonhypoxemic subjects is close to the mean value reported by Laursen et al. (13), whereas hypoxemic subjects reached significantly lower levels. These results may be another explanation of the lack of hypoxemic subjects in the study of Laursen et al. (13). Supporting this hypothesis, we found that BR and $\mathrm{V}_{\mathrm{T}} / \mathrm{FVC}$ were correlated with $\mathrm{SaO}_{2}$ at the end of exercise. Hence, the size of lung could be a significant factor in EIAH in prepubescent children as it was observed in adult trained women $(4,11)$ and suggests that the higher pulmonary ventilation could lead to a mechanical constraint at maximal exercise intensity, with the consequential effect on exercise $\mathrm{SaO}_{2}$. Nonetheless, even if hypoxemic subjects seem to ventilate near their mechanical lung limits, no difference was observed in Peto $_{2}$, Petco $2, \dot{\mathrm{V}}_{\mathrm{E}} / \dot{\mathrm{V}}_{2}$, and $\dot{\mathrm{V}}_{\mathrm{E}} / \dot{\mathrm{V}}_{\mathrm{CO}_{2}}$ between both groups, which supposes that ventilation at maximal exercise was adequate and that other mechanisms seem to be implicated in EIAH in children at maximal workload, e.g. $\dot{\mathrm{V}}_{\mathrm{A}} / \mathrm{Q} \mathrm{c}$ mismatch or pulmonary diffusion limitation $(2,5,9)$.

EIAH and sex. In the present study, EIAH occurred in a similar proportion of girls (25\%) and boys (30\%). Moreover, in agreement with Nagano et al. (30), no sex difference was found in ventilatory response to exercise, a possible mechanism in the onset of EIAH as discussed above. Nevertheless, this result should be interpreted cautiously because the girls were slightly younger $\left(\sim 1\right.$ y) than boys. Sex seems to affect $\dot{\mathrm{V}}_{\mathrm{O}_{2 \max }}$ and $\dot{\mathrm{V}}_{\mathrm{E}}$ at maximal exercise, found to be lower in girls than in boys despite a similar extracurricular physical activity level. Moreover, mean arterial desaturation at maximal exercise was less pronounced in girls than in boys. This could be explained by the fact that the metabolic demand, i.e. $\dot{V}_{\mathrm{O}_{2 \max }}$, was lower in our girls than in our boys $\left(40.2\right.$ versus $\left.51.2 \mathrm{~mL} \cdot \mathrm{min}^{-1} \cdot \mathrm{kg}^{-1}\right)$, likewise for achieved $\dot{V}_{\mathrm{E}}(66.9 \pm 4.6$ versus $62.7 \pm 3.3$ $\mathrm{L} / \mathrm{min}$ ). This could result in a better adequacy between metabolic demand and lung capacity in girls. In addition, only the lean body mass is involved in the metabolic demand, whereas relative $\dot{\mathrm{V}}_{2 \max }$ does not differentiate lean and fat mass. Thus, the higher body fat mass in girls than boys could explain partly the difference in $\dot{V}_{O_{2 \max }}$ between both sexes. However, there were a small number of girls in the present study $(n=8)$, and results on sex differences and EIAH need obviously to be confirmed with a larger population of girls.

In conclusion, prepubescent sportive children may exhibit EIAH for values of $\dot{\mathrm{V}}_{2 \text { max }} \geq 43 \mathrm{~mL} \cdot \mathrm{min}^{-1} \cdot \mathrm{kg}^{-1}$. Nevertheless, the mechanisms remain unclear and need to be investigated more accurately. In addition, it would be of great interest to study, during growth, the long-term development and consequence of this EIAH, known for its detrimental effect on performance in sports-trained adults.

Acknowledgments. We thank our subjects for enthusiastic participation in this study and Yannick Castannet, Audrey Koïtka, and Grégory Dupont for technical support.

\section{REFERENCES}

1. Dempsey JA, Hanson PG, Henderson KS 1984 Exercise-induced arterial hypoxaemia in healthy human subjects at sea level. J Physiol 355:161-175

2. Dempsey JA, Wagner PD 1999 Exercise-induced arterial hypoxemia. J Appl Physiol 87:1997-2006

3. Powers SK, Martin D, Dodd S 1993 Exercise-induced hypoxaemia in elite endurance athletes. Incidence, causes and impact on $\dot{\mathrm{V}}_{2}$. Sports Med 16:14-22

4. Harms CA, McClaran SR, Nickele GA, Pegelow DF, Nelson WB, Dempsey JA 1998 Exercise-induced arterial hypoxaemia in healthy young women. J Physiol 507:619628

5. Prefaut C, Durand F, Mucci P, Caillaud C 2000 Exercise-induced arterial hypoxaemia in athletes: a review. Sports Med 30:47-61

6. Powers SK, Lawler J, Dempsey JA, Dodd S, Landry G 1989 Effects of incomplete

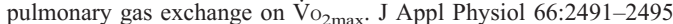

7. Durand F, Mucci P, Prefaut C 2000 Evidence for an inadequate hyperventilation inducing arterial hypoxemia at submaximal exercise in all highly trained endurance athletes. Med Sci Sports Exerc 32:926-932

8. Harms CA, Stager JM 1995 Low chemoresponsiveness and inadequate hyperventilation contribute to exercise-induced hypoxemia. J Appl Physiol 79:575-580

9. Hopkins SR, Gavin TP, Siafakas NM, Haseler LJ, Olfert IM, Wagner H, Wagner PD 1998 Effect of prolonged, heavy exercise on pulmonary gas exchange in athletes. J Appl Physiol 85:1523-1532

10. Rice AJ, Thornton AT, Gore CJ, Scroop GC, Greville HW, Wagner H, Wagner PD, Hopkins SR 1999 Pulmonary gas exchange during exercise in highly trained cyclists with arterial hypoxemia. J Appl Physiol 87:1802-1812

11. Wetter TJ, St Croix CM, Pegelow DF, Sonetti DA, Dempsey JA 2001 Effects of exhaustive endurance exercise on pulmonary gas exchange and airway function in women. J Appl Physiol 91:847-858 
12. Rowland T 1996 Developmental Exercise Physiology. Human Kinetics, Champaign, IL, pp $27-157$

13. Laursen PB, Tsang GC, Smith GJ, van Velzen MV, Ignatova BB, Sprules EB, Chu KS, Coutts KD, McKenzie DC 2002 Incidence of exercise-induced arterial hypoxemia in prepubescent females. Pediatr Pulmonol 34:37-41

14. Tanner J 1962 Growth at Adolescence. Blackwell Scientific, Oxford pp 325

15. Durnin JV, Rahaman MM 1967 The assessment of the amount of fat in the human body from measurements of skinfold thickness. Br J Nutr 21:681-689

16. Deheeger M, Rolland-Cachera MF, Fontvieille AM 1997 Physical activity and body composition in 10 year old French children: linkages with nutritional intake? Int J Obes Relat Metab Disord 21:372-379

17. Buchfuhrer MJ, Hansen JE, Robinson TE, Sue DY, Wasserman K, Whipp BJ 1983 Optimizing the exercise protocol for cardiopulmonary assessment. J Appl Physiol 55:1558-1564

18. American Thoracic Society 1987 Standardization of spirometry-1987 update. Statement of the American Thoracic Society. Am Rev Respir Dis 136:1285-1298

19. Johnson BD, Weisman IM, Zeballos RJ, Beck KC 1999 Emerging concepts in the evaluation of ventilatory limitation during exercise: the exercise tidal flow-volume loop. Chest 116:488-503

20. Medoff BD, Oelberg DA, Kanarek DJ, Systrom DM 1998 Breathing reserve at the lactate threshold to differentiate a pulmonary mechanical from cardiovascular limit to exercise. Chest 113:913-918

21. Cooper DM, Kaplan MR, Baumgarten L, Weiler-Ravell D, Whipp BJ, Wasserman K 1987 Coupling of ventilation and $\mathrm{CO}_{2}$ production during exercise in children. Pediatr Res 21:568-572

22. Martin D, Powers S, Cicale M, Collop N, Huang D, Criswell D 1992 Validity of pulse oximetry during exercise in elite endurance athletes. J Appl Physiol 72:455-458

23. Powers SK, Dodd S, Freeman J, Ayers GD, Samson H, McKnight T 1989 Accuracy of pulse oximetry to estimate $\mathrm{HbO}_{2}$ fraction of total $\mathrm{Hb}$ during exercise. J Appl Physiol 67:300-304
24. American Association for Respiratory Care 1992 Clinical practice guideline. Exercise testing for evaluation of hypoxemia and/or desaturation. Respir Care 37:907-912

25. Mucci P, Prioux J, Hayot M, Ramonatxo M, Prefaut C 1998 Ventilation response to $\mathrm{CO}_{2}$ and exercise-induced hypoxaemia in master athletes. Eur J Appl Physiol Occup Physiol 77:343-351

26. Rice AJ, Scroop GC, Gore CJ, Thornton AT, Chapman MA, Greville HW, Holmes MD, Scicchitano R 1999 Exercise-induced hypoxaemia in highly trained cyclists at 40\% peak oxygen uptake. Eur J Appl Physiol Occup Physiol 79:353-359

27. Aguilaniu B, Flore P, Maitre J, Ochier J, Lacour JR, Perrault H 2002 Early onset of pulmonary gas exchange disturbance during progressive exercise in healthy active men. J Appl Physiol 92:1879-1884

28. Ohuchi H, Kato Y, Tasato H, Arakaki Y, Kamiya T 1999 Ventilatory response and arterial blood gases during exercise in children. Pediatr Res 45:389-396

29. Harms CA, McClaran SR, Nickele GA, Pegelow DF, Nelson WB, Dempsey JA 2000 Effect of exercise-induced arterial $\mathrm{O}_{2}$ desaturation in $\mathrm{V}_{O_{2 m a x}}$ in women. Med Sci Sports Exerc 32:1101-1108

30. Nagano Y, Baba R, Kuraishi K, Yasuda T, Ikoma M, Nishibata K, Yokota M, Nagashima M 1998 Ventilatory control during exercise in normal children. Pediatr Res 43:704-707

31. McConnell AK, Semple ES, Davies CT 1993 Ventilatory responses to exercise and carbon dioxide in elderly and younger humans. Eur J Appl Physiol Occup Physiol 66:332-337

32. McConnell AK, Semple ES, Davies CT 1996 Ventilatory sensitivity to carbon dioxide: the influence of exercise and athleticism. Med Sci Sports Exerc 28:685691

33. Pianosi P, Wolstein R 1996 Carbon dioxide chemosensitivity and exercise ventilation in healthy children and in children with cystic fibrosis. Pediatr Res 40:508-513 